\title{
A growing urban problem
}

\author{
Cities and Complexity: Understanding \\ Cities with Cellular Automata, Agent- \\ Based Models, and Fractals \\ by Michael Batty \\ MIT Press: 2005.648 pp. $\$ 60, £ 38.95$
}

\section{Frank Schweitzer}

Urban growth is one of the biggest challenges for humankind in the twenty-first century. The world's urban population is at present estimated to be growing by about 50 million people per year. This growth is still almost exponential, and saturation may be reached only by the middle of the century. So there is much discussion about estimates of land consumption, the manageable size of megacities, and simple ways to structure, if not to control, this vast spread of urbanization.

For this, a better understanding of the spatial dynamics of urban growth should be a precondition. In fact, urban planning, urban geography, urban economics and other related disciplines have put quite some effort into this problem. Although they provide insight into some details, they do not present the big picture of generic mechanisms underlying these complex dynamics. So it is reasonable to consider whether the theory of complex systems developed in different scientific areas over the past 30 years may provide a suitable toolbox for gaining such an insight.

In Cities and Complexity, Mike Batty, an expert in the area of urban modelling, unfolds the different aspects of urban change in relation to complex systems theory. The focus is on models and computer simulations: there is no introduction explaining what we already know about cities and growth, or any attempt at orientation on the phenomenological side. This is good and bad at the same time. Some readers will certainly miss a clear relation between cities as we know them and the rather abstract models and results for specific dynamic features, such as segregation or polynucleated growth. Others, however, will appreciate the insights into generic features of urban dynamics that can only be highlighted at the abstract level used. As the author puts it, the focus is "largely on experiments with models that provide us with analogies as to how cities develop and evolve".

These analogies are investigated on very different modelling levels relating to the different scales of urban dynamics. Models of fractal growth show analogies to the morphological structure of urban aggregates, and models of moving agents resemble the motion of pedestrians on streets and inside buildings. Many of these models use cellular automata, which allow a broad range of topics such as land-use patterns or regeneration of urban areas to be addressed. A 'desktop simulator' is described in more detail in one of the chapters, tempting

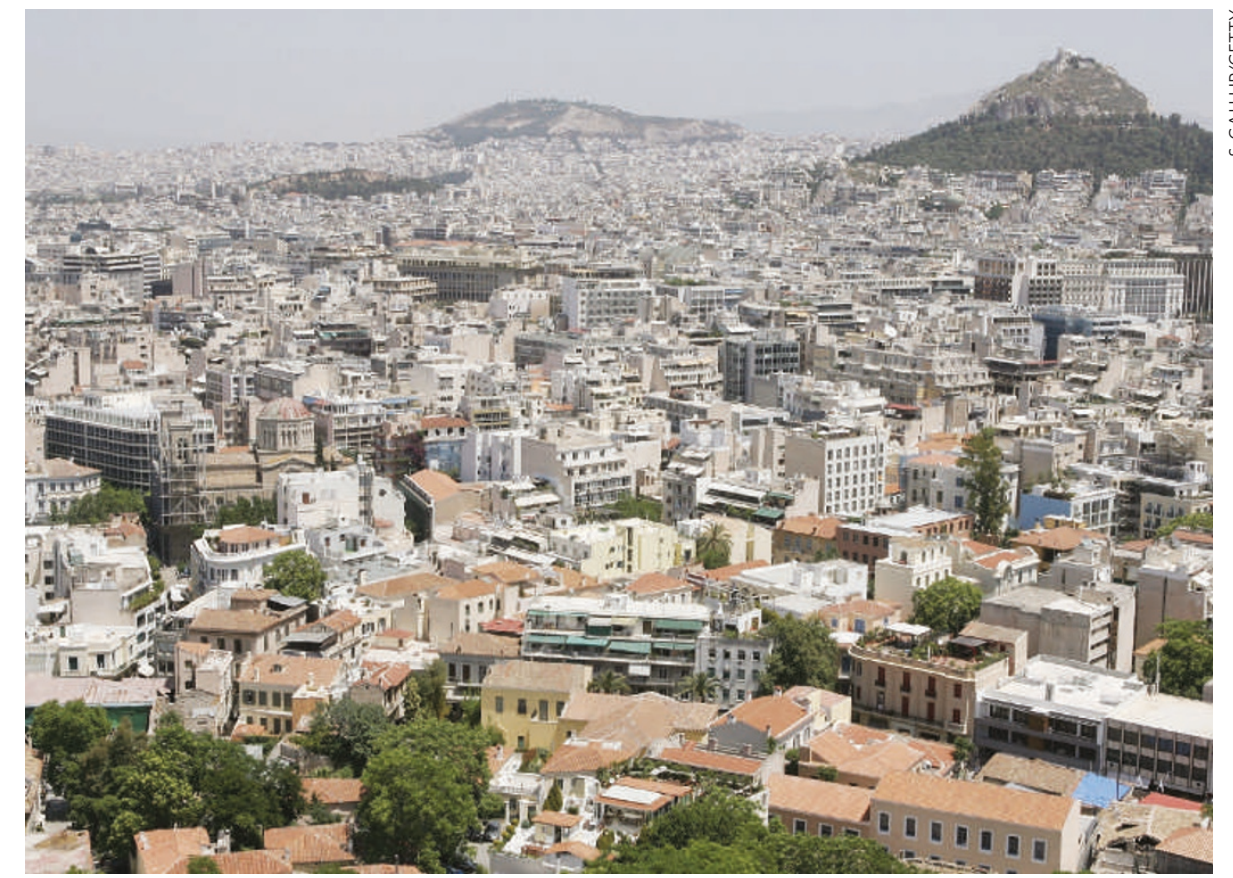

The expanding sprawl of cities such as Athens highlights a need to understand urban growth.

the reader to play with the ideas discussed in the book. Unfortunately, the plan to put examples from the book together with related material on a website (www.complexcity.info) is yet to be realized.

The book certainly succeeds in making the topic of urban growth accessible and interesting to those already familiar with formal modelling of complex systems. However, practitioners in urban planning may find some of the concepts and models too abstract and 'academic' to give solutions. But at least they should agree that this complex-systems perspective sheds new light on to the dynamics of urban evolution by highlighting relations to seemingly distant phenomena, such as swarming or epidemics. Apart from the necessary technical details of the models, the author gives a number of illustrative examples and facts to elucidate his viewpoint, widening the appeal of the book to a broader audience. Frank Schweitzer is chair of systems design at ETH Zürich, Kreuzplatz 5, 8032 Zürich, Switzerland.

\section{A healthy interest}

\section{Doctor Franklin's Medicine \\ by Stanley Finger \\ University of Pennsylvania Press: 2006. \\ 400 pp. \$39.95, £26}

\section{W. F. Bynum}

If the creation of the American Republic can be taken as a high point of the Enlightenment, then Benjamin Franklin (1706-1790) is a central figure. Unlike many of the other Founding Fathers, he came from a humble background and had a gentle sense of humour. Self-taught, he made his initial reputation as a printer and publisher, especially of Poor Richard's Almanac, a phenomenally successful annual in a crowded market. In the almanac, Franklin's alter ego, Poor Richard, offered advice and homespun wisdom about health and much else besides. In his own persona, Franklin was to do the same for the rest of his long life.

In Doctor Franklin's Medicine, Stanley Finger has assembled Franklin's many interactions with medicine, health and doctors. Given the attention that the iconic Franklin has already attracted from historians, there are few surprises here, but the impact of the whole package is formidable. Most doctors would have been well satisfied to have so changed the face of medicine; Franklin did it almost incidentally, in the midst of a busy life as a natural philosopher, diplomat and man of the world.

Franklin lived most of the second half of his life in England and France, on official business first on behalf of Pennsylvania, and then of the new nation. He was known abroad primarily as an electrician, a word that in those days carried rather different connotations. Through his famous experiment with a kite and lightning, 
he did for electricity what Newton had done with gravity: related the heavens to the Earth. It was as an electrician that Franklin was lured into the practice of medicine: he was several times asked to electrify patients with nervous disorders. Always suspicious of grand speculation, and a careful observer, he never claimed more for the therapeutic potential of his brainchild than his own experience warranted.

Several of his interactions with medicine have biographical poignancy. He advocated inoculation for smallpox (he died shortly before Edward Jenner introduced vaccination), but lost one of his own uninoculated children to the disease. Ever alert to the dangers of lead poisoning (among printers who used lead type, as well as other occupational groups), Franklin collaborated with George Baker, the British physician who exposed its high levels in cider and other alcoholic drinks kept in lead vats. Franklin himself loved Madeira and port, two likely sources of toxic levels of the metal. He suffered from gout and bladder stones, a probable consequence of the poison to which he helped alert the public.

There were other inconsistencies in his philosophy of health. He advocated the healthgiving properties of fresh air, although as a social man he thrived in the clubs of urban centres such as Philadelphia, London and Paris. He also preached the virtues of exercise, believing that swimming was an undervalued activity, and swam even after he became very corpulent in his old age.

Other medical contributions were unambiguous. Franklin invented and wore bifocals, and used an ingenious mechanical arm to grasp books and other objects on high shelves, a natural consequence of his large private library. He was a founder of the first public hospital in America, the Pennsylvania Hospital. So close was his relation to medicine that the French occasionally assumed that he was medically qualified; in fact, 'Doctor Franklin' had several honorary degrees but no formal medical training. Nor did he apparently need it. He moved easily in medical and scientific circles, respected by the French and welcomed in Britain even after the United States had severed its ties with the mother country. Franklin had signed the Declaration of Independence, but he was always a man of peace. As he wrote in 1783: "There never was a good war, or a bad peace."

W. F. Bynum is at the Wellcome Trust Centre for the History of Medicine, University College London, London NW12BE, UK.

\section{MORE ON BENJAMIN FRANKLIN The First Scientific American: Benjamin Franklin and the Pursuit of Genius by Joyce E. Chaplin \\ Basic Books: 2006. 362 pp. $\$ 27.50$}

\section{Home from home}

\section{History is brought to life at Benjamin Franklin's house in London.}

\begin{abstract}
Colin Martin
Arguably the most famous American in the Age of the Enlightenment, Benjamin Franklin achieved scientific fame by flying a silk kite with a wire rod at one end and a key at the other into a thunderstorm in Philadelphia in 1752. He thus demonstrated that lightning consists of flashes of electricity.

During his long life, Franklin
\end{abstract} made many contributions to several branches of science. He found research a welcome respite from his role negotiating the turbulent complexities of contemporary diplomacy, including the repeal of stamp duty, which the British parliament had imposed on its American colonies in 1765 .

This year marks the 300th anniversary of Franklin's birth, the cue for activities around the world (see www.benfranklin300.org). It has been celebrated in London by the public opening of the 1730s Georgian townhouse, at 36 Craven Street, where he lived for 16 years as an agent for the Pennsylvania Assembly. The newly restored house serves as a museum and education centre (see www.benjaminfranklinhouse.org).

During his years in London, Franklin invented bifocal spectacles; developed a fuel-efficient fireplace draught called the Franklin stove; installed a new, more effective lightning rod on the dome of St Paul's Cathedral; and invented the glass armonica (or harmonica), with its haunting

sound described as "the voice of angels".

He worked with Joseph Priestley on experiments that led to the discovery of oxygen; recorded the effects of the Gulf Stream and other ocean currents; investigated canal depths and their implication for transport; and demonstrated the veracity of the old adage that oil calms

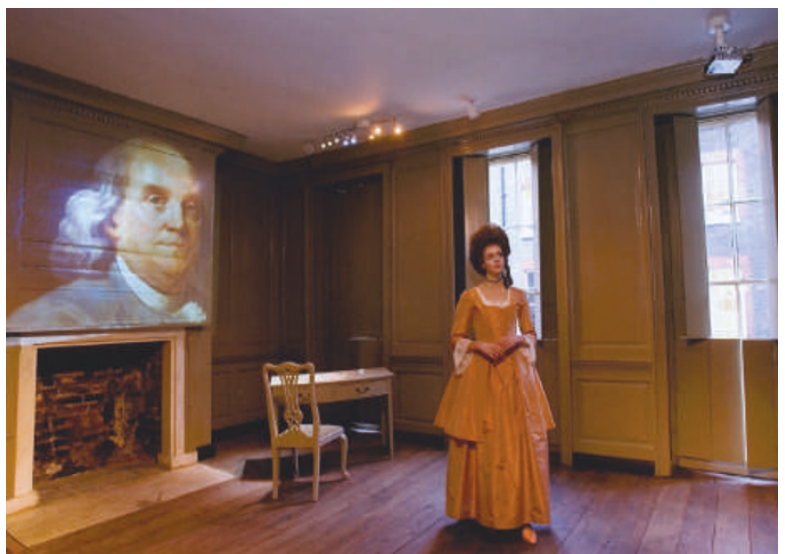

Tour de force? Polly acts as guide in Franklin's London home.

account of coagulation. Hewson lived at the house from 1770 to 1774 after he married Polly Stevenson, the daughter of Franklin's landlady. The medical-history room in the science study centre continues this tradition with ingenious models and touch-screen computers to encourage schoolchildren to think about how the human body works.

The house is interpreted for visitors in an evocative 'museum as theatre' tour, which incorporates state-of-the art audiovisual display techniques and an actress in eighteenth-century dress who plays the role of Polly (see picture). Polly's interest in Franklin's diplomacy and science made her one of his closest confidantes. "After writing six folio pages of scientific philosophy to a young girl, is it necessary to finish such a letter with a compliment?" asks Franklin during an audiovisual presentation. "Is not such a letter of itself a compliment?"

Despite his skilled diplomacy,

troubled water, on a windswept pond in the London suburb of Clapham. Some of these achievements are recreated as hands-on experiments for school children at the centre as an introduction to scientific methodology.

During the recent restoration of the house, some 1,200 human bones were found in the basement. They were identified as remains from an anatomy school founded at the house by William Hewson, a British anatomist who identified the role of fibrinogen in 1770 and gave the first valid and his satirical Rules By Which a Great Empire May be Reduced to a Small One, written in 1773 to warn the intransigent British of the dangers of taking a hard line against hot-headed American colonists, Franklin failed to avert the War of Independence. In 1775, he hurriedly left Craven Street. By the time he had returned to Philadelphia, the American Revolution had begun. He died in 1790 at Passy near Paris, with Polly and Franklin's own daughter Sally at his bedside. Colin Martin is a writer based in London. 